Objectives: To identify HLA alleles associated with susceptibility to develop an IMID in Paraguayan patients controlled in a reference centre.

Methods: Paraguayan IMID patients were recruited from the Rheumatology Department of Hospital de Clínicas, Paraguay. IMID HLA // frequencies where compared with a control group of 50 unrelated individuals without disease and from the same geographic origin. Genotyping for HLA was performed using Luminex PCR technology. The association analysis with the IMIDs risk was performed using the chi-square allelic test.

Results: 249 IMID patients (95 lupus, 104 rheumatoid arthritis and 50 systemic sclerosis) where included. Of these $84,4 \%$ were women with an average age of $43,4( \pm 14)$. Comparing the haplotypes profiles for the $5 \mathrm{HLA}$ class II genes between the patients and the healthy controls, in the risk association analysis, the association of the known risk allele was corroborated HLADRB1*03:01 ( $\mathrm{p}=2 \mathrm{e}-06$, OR:14,97). A significant association was identified between the allele HLADRB1 * 08:02 ( $\mathrm{p}=0.0271, \mathrm{OR}: 0,13)$ and HLADRB1 * 08:07 ( $\mathrm{p}=0.0133$, OR: 0.08$)$. In the gene HLADQA1, 1 allele associated with the IMIDs were found, the HLADQA $1{ }^{*} 04: 01$ ( $p=1.4 \mathrm{e}-05$, OR: 0.06). In the HLADPB1 gene 3 alleles associated with the IMIDs were identified: $\operatorname{HLADPB} 1{ }^{*} 02: 01 \quad(p=4.2 e-05$, OR: 82.91$)$, HLADPB1*03:01 ( $p=2 e-06$, OR: 14.97), HLADPB1*04:01 ( $p=1.5 e-05$ OR: 34.55$)$. Different associations between IMIDs and alleles was identify (table 1).

Abstract AB0005 - Table 1. List of associated alleles stratified by disease

\begin{tabular}{|c|c|c|}
\hline $\begin{array}{l}\text { ALLELE (Systemic Lupus Erythematosus } \\
\text { Cohort) }\end{array}$ & $\begin{array}{c}\text { P- } \\
\text { valour }\end{array}$ & OR \\
\hline HLADQA ${ }^{*} 02: 01$ & 0.0253 & 14 \\
\hline ALLELES (Rheumatoid Arthritis Cohort) & $\begin{array}{c}\text { P- } \\
\text { valour }\end{array}$ & OR \\
\hline HLADRB1*08:02 & 0.0367 & 0.11 \\
\hline HLADPB1*02:01 & 0.0003 & 54.62 \\
\hline HLADPB1*03:01 & 0.0010 & 7.92 \\
\hline HLADPB1*04:01 & 0.0001 & 29.69 \\
\hline HLADQA $1{ }^{*} 02: 01$ & 0.0467 & 0.24 \\
\hline HLADQA $1{ }^{*} 04: 01$ & 0.002 & 0.07 \\
\hline HLADPA1*02:01 & 0.0022 & 0.029 \\
\hline ALLELES (Scleroderma Cohort) & $\begin{array}{c}\text { P- } \\
\text { valour }\end{array}$ & OR \\
\hline HLADPB1*02:01 & 0.0003 & 82.33 \\
\hline HLADPB1*03:01 & 0.0094 & 8.44 \\
\hline HLADPB $1{ }^{*} 04: 01$ & 0.0001 & 47.50 \\
\hline HLADQA $1{ }^{*} 04: 01$ & 0.0013 & 0.06 \\
\hline
\end{tabular}

Conclusions: In the genetic association analysis, already known associations have been replicated and new ones previously unpublished have been identified in Paraguayan IMIDs patients. This is the first genetic association study in IMID patients Paraguayan origin.

Disclosure of Interest: None declared

DOI: 10.1136/annrheumdis-2018-eular.5021

\section{AB0006 MIR-26A POLYMORPHISM IS ASSOCIATED WITH SUSCEPTIBILITY OF RHEUMATOID AND PSORIATIC ARTHRITIS}

J. Swierkot ${ }^{1}$, R. Sokolik ${ }^{1}$, M. Kozlowski ${ }^{2}$, L. Korman ${ }^{1}$, P. Wiland ${ }^{1}$, K. BoguniaKubik $^{2} .{ }^{1}$ Department of Rheumatology and Internal Medicine, Medical University; ${ }^{2}$ Laboratory of Clinical Immunogenetics and Pharmacogenetics, Hirszfeld Institute of Immunology and Experimental Therapy, Polish Academy of Sciences, Wroclaw, Poland

Background: Serum levels of miR-26a has been reported to act as potential biomarker of rheumatic diseases.

Objectives: The aim of the study was to analyse the genetic variation and expression of miR-26a as potential diagnostic and/or prognostic markers of rheumatoid diseases.

Methods: The miR-26a polymorphism was examined in 111 patients with rheumatoid arthritis (RA), 86 patients with psoriatic arthritis (PsA) and 162 healthy blood donors that served as a control group.

Genotyping for miR-26a rs7372209 was performed using a LightSNiP assay. For analysis of the miR-26a expression, RNA was isolated from sera of 15 RA patients (before and 3 months after anti-TNF treatment) and 10 controls (NucleospinmiRNA Plasma; MACHEREY-NAGEL GmbH and Co. KG) followed by cDNA synthesis (TaqMan MicroRNA Reverse Transcription Kit; Applied BiosystemsTM by Life Technologies) and Real-time PCR amplifications with hsa-miR-26a TaqMan specific and U6 snRNA control primers for each probe. The results were analysed using the $(\Delta \Delta \mathrm{Ct})$ calculations.

Results: It was found that the presence of miR-26a TT genotype (rs7372209) more than 5 times increases the risk of $R A(O R=5.28, p=0.003)$ while the presence of $C C$ homozygotes is associated with the risk of PsA (OR=1.77, $p=0.037)$.
There was no significant difference in the miR-26a serum levels between patients and controls. Also miR-26a serum levels did not significantly differed between RA patients before, 3 and 6 months after the implementation of biological therapy with TNF-alpha inhibitors.

Conclusions: These results imply that miR-26a rs7372209 allelic variants differentially affect the risk of rheumatoid and psoriatic arthritis while anti-TNF biological treatment seems not to affect the miR-26a expression in RA patients.

Disclosure of Interest: None declared

DOI: 10.1136/annrheumdis-2018-eular.6673

\section{$\mathrm{AB} 0007$ \\ ASSOCIATION AT SYSTEMIC LEVELS OF CYTOKINE MRNAS AND PROTEIN QUANTITIES IN RHEUMATOID ARTHRITIS}

I. Manolova ${ }^{1}$, M.G. Ivanova ${ }^{2}$, G. Vasilev ${ }^{3}$, R. Stoilov², L. Miteva ${ }^{1}$, S. Stanilova ${ }^{1}$. ${ }^{1}$ Department of Molecular Biology, Immunology and Medical Genetics, Medical Faculty, Trakia University, Stara Zagora; ${ }^{2}$ Clinic of Rheumatology, University Hospital "St. Iv. Rilski", Medical Faculty, Medical University; ${ }^{3}$ Laboratory of Clinical immunology, University Hospital "St. Ivan Rilski", Medical Faculty, Medical University, Sofia, Bulgaria

Background: Rheumatoid arthritis (RA) is an autoimmune inflammatory disease, characterised by chronic synovitis, bone and cartilage destruction, as well as systemic manifestation. In accordance with the pivotal role of cytokines in autoimmunity and their impact as biomarkers, we analysed gene expression at both mRNA and protein levels of several cytokines in peripheral blood of RA patients. Objectives: The aim of the present study was to investigate the gene expressions at mRNA and protein levels of main pro-inflammatory (TNF- $\alpha$, IL18, IL12p40; IL-23, IL-6) and immunosuppressive (TGF- $\beta 1$ and IL10) cytokines and transcription factor Foxp3 in peripheral blood of RA patients.

Methods: Total RNA from peripheral blood was isolated from 32 patients match ing the ACR/EULAR 2010 criteria for RA and 27 healthy controls. Quantitative realtime polymerase chain reaction was performed for the 8 genes of interests, using the TaqMan detection system. Relative quantitative evaluation of mRNAs was performed by the comparative $\Delta \Delta \mathrm{Ct}$ method and results were presented as $\mathrm{n}$-fold mean difference (RQ-relative quantity) of target genes relative to calibrator (healthy controls) after normalisation to the reference genes (GAPDH and 18srRNA). Serum quantities of cytokines were measured by ELISA.

Results: From studied pro-inflammatory cytokine genes, we found down-regulation in the following order: IL6 >TNFA>IL12B; up regulation of IL23A and no change in IL18 gene expression in RA patients group compared to healthy controls. For anti-inflammatory genes we detected significantly increased quantity for IL10 mRNA and no change for TGFB1 mRNA. The most profound down-regulation (more than 7-fold) was observed for IL6 gene $(p<0.001)$, while the serum level of the same cytokine was significantly increased as compared to the same controls. The similar tendency was observed in the expression of TNFA, which gene expression was approximately 2-fold down-regulated, whereas serum levels were increased. IL12B mRNA were slightly but not significantly decreased $(R Q=0.709$; $\mathrm{p}=0.169$ ) in RA patients. An upregulation of IL-23 was detected for IL23A gene $(R Q=2.422, p=0.002)$ and serum level of IL-23 as well.

TGFB1 mRNA levels were approximately equal in patients and controls in contrast to IL-10, which was upregulated in both $\mathrm{mRNA}(\mathrm{RQ}=1.6 ; \mathrm{p}=0.034)$ and serum levels (over 6.6 fold; $p<0.05$ ). In addition, mRNA expression of FoxP3, a master transcription factor for Treg subset was also down-regulated over 4-fold in RA patients $(p<0.001)$. A positive correlation was found between gene expression of IL6 with Foxp3, TNFA and TGFB1 in RA ( $r=0.744, p=0.004 ; r=0.6, p=0.03$; $r=0.556, p=0.048$, respectively)

Conclusions: Our results demonstrated significant differences in the expression of mRNA encoded cytokines and their protein quantities at systemic level of RA patients, mostly on IL-23, IL-6 and TNF-alpha.

Disclosure of Interest: None declared

DOI: 10.1136/annrheumdis-2018-eular.3330

\section{AB0008 1 CROSS-TALK BETWEEN BONE TURNOVER AND CARDIOVASCULAR DISEASE. ASSOCIATION OF MICRORNAS EXPRESSION, FRACTURE AND ABDOMINAL AORTIC CALCIFICATIONS}

M.-E. Pickering ${ }^{1,2}$, M. Croset $^{1,2}$, M. Millet $^{1,2}$, E. Sornay-Rendu ${ }^{1,2}$, J.-

C. Rousseau ${ }^{1,2}$, O. Borel ${ }^{1,2}$, P. Szulc ${ }^{1,2}$, R. Chapurlat ${ }^{1,2}$. ${ }^{1}$ Hospices Civils de Lyon;

${ }^{2}$ INSERM UMR 1033, Lyon, France

Background: MicroRNAs (miRs) have emerged as pivotal epigenetic key actors of gene regulation and several miRs have been shown to be at the crossroads of angiogenesis and of bone turnover, taking part in the calcification process by acting on osteoblasts and osteoclasts. ${ }^{1}$ Calcification of the aortic media is highly 
regulated and involves numerous factors, including calcium deposal and other bone remodelling factors. ${ }^{2}$

Objectives: The objective of this study was to find a signature of miRs linked both to osteoporotic fracture risk and abdominal aortic calcification (AAC).

The first outcome was the link between miRs levels at baseline and incident osteoporotic fractures (IOF) during 20 years; the second outcome was the link between miRs levels at baseline and the increase in AAC during 17 years.

Methods: Post-menopausal women older than 50 years from the OFELY cohort (Os des FEmmes de LYon) were selected if they had available serums at inclusion, and available data for each outcome.

3 miRs selected after literature review because of their impact on vascular calcification and bone turnover (miRs 26a-5p, 34a-5p, and 223-5 p) were measured at baseline. Bioassays of miRs was conducted with miRCURY Biofluids (Exiqon) extraction kit, TaqMan Life Technologies protocol, and QuantStudio 7 flex (Applied Biosystems) for RNA quantification. Results are expressed by relative quantification of Cycle threshold (Ct).

Results: A sample of 434 age-matched women (63 [57-72] years old), 50\% with incident osteoporotic fracture during the 20 years of follow-up, was included. 183 women had available data to explore AAC; 93 had an increase in Kauppila score in 17 years (58 [55-61] years old), 90 did not (55 [53-58] years old).

No significant link was underlined between miRs and IOF (miR-26: 1.06 [0.851.27] vs 0.99 [0.85-1.17], $p=0.07$; miR-34: 1.15 [0.53-1.87] vs 1.26 [0.60-2.07], $\mathrm{p}=0.35$; miR-223: 1.01 [0.68-1.43] vs 10.05 [0.72-1.56], $p=0.32)$.

No miR was significantly linked to an increase in AAC (miR-26: 1.09 [0.94-1.28] vs 1.10 [0.89-1.30], $p=0.95$; miR-34: 0.78 [0.46-1.21] vs 0.73 [0.38-1.50], $\mathrm{p}=0.90$; miR-223: 0.97 [0.69-1.22] vs 0.78 [0.56-1.22], $\mathrm{p}=0.11$ ).

Conclusions: No association was observed between the 3 tested miRs and IOF or increase in AAC. Larger studies are necessary to select interesting epigenetic pathways reproductible on wider population.

\section{REFERENCES:}

[1] Krzeszinskia JY, Wei W, Huynh H, Jin Z, Wang X, Chang T-C, et al. miR34a Blocks Osteoporosis and Bone Metastasis by Inhibiting Osteoclastogenesis and Tgif2. Nature 2014 Aug 28;512(7515):431.

[2] Szulc P. Abdominal aortic calcification: A reappraisal of epidemiological and pathophysiological data. Bone 2016 Mar;84:25-37.

Disclosure of Interest: None declared

DOI: 10.1136/annrheumdis-2018-eular.5792

\section{AB0009 GENETIC ASSOCIATION OF MITOCHONDRIAL DNA POLYMORPHISMS WITH BEHCEET'S DISEASE IN A KOREAN POPULATION}

M.-H. Kwon ${ }^{1}$, C.-I. Joung ${ }^{1}$, S.-J. Yoo ${ }^{2}$, S.W. Kang ${ }^{2}$, I.S. Yoo ${ }^{2}$, J. Kim², I.A. Choi ${ }^{3}$ M.-K. Lim ${ }^{4} .{ }^{1}$ Internal medicine, Konyang university; ${ }^{2}$ Internal medicine, Chungnam national university, Daejeon; ${ }^{3}$ Internal medicine, Chungbuk national university, Chungju; ${ }^{4}$ Internal medicine, Eulji university, Daejeon, Korea, Republic of Ireland

Background: Behcet's disease(BD) is an inflammatory multi-genetic disorder with unknown etiology. In the previous study, we sequenced whole mitochondrial nucleotides from blood of $20 \mathrm{BD}$ patients and 10 sex-, age-matched healthy controls, m.248A $>\mathrm{G}, \mathrm{m} .709 \mathrm{G}>\mathrm{A}, \mathrm{m} .3970 \mathrm{C}>\mathrm{T}, \mathrm{m} .6392 \mathrm{~T}>\mathrm{C}, \mathrm{m} .6962 \mathrm{G}>\mathrm{A}$, m.10310G $>A, \quad m .10609 T>C, \quad m .12406 G>A, \quad m .12882 C>T, \quad m .13928 G>C$, $\mathrm{m} .16129 \mathrm{G}>\mathrm{A}$, and $\mathrm{m} 16304 \mathrm{~T}>\mathrm{C}$ were more frequently observed in patients group than healthy control without statistical significance. While, m.304C>A, m.3010G $>A, m .4883 C>T, m .5178 C>A$, and $m .14668 \mathrm{C}>\mathrm{T}$ were more frequent in control group $(p=0.008,0.026,0.007,0.007$, and 0.026 , respectively). m.16182A $>C, m .16183 A>C, m .16189 T>C$ were associated with uveitis $(p=0.041$ 0.022 , and 0.014 , respectively).

Objectives: We performed a follow-up study to validate these possible associations in larger groups.

Methods: Whole blood or buffy coat were collected from 98 BD patients from four university hospitals located in Chung-Cheong district of Republic of Korea, 196 age-, sex-matched healthy controls from Konyang University Hospital. Above mentioned 20 targeted mitochondrial DNA(mtDNA) genomes were analysed using MassARRAY ${ }^{\boxplus}$ system(Agena Bioscience, Inc., San Diego, CA, USA) for $\mathrm{m} .709$, m.3010, m.4883, m.6392, m.6962, m.10310, m.10609, m.12406, m.12882, m.13928, and m.14668; Sanger sequencing for m.248, m.304, m.5178, m.16129, m.16182, m.16183, m.16189, and m.16304; and TaqMan-based genotyping assay(Applied Biosystems, Foster City, CA, USA) for m.3970. Results were compared with the revised Cambridge Reference Sequence (rCRS). Chi square or Fisher's exact test were used to analyse association of mtDNA alterations between groups and between mtDNA alterations and clinical/laboratory characteristics.

Results: Presence of m.248A $>$ G, m.304C $>A$, m.709G $>A, \quad m .3010 G>A$ m.3970C $>\mathrm{T}, \mathrm{m} .4883 \mathrm{C}>\mathrm{T}, \mathrm{m} .5178 \mathrm{C}>\mathrm{A}, \mathrm{m} .6392 \mathrm{~T}>\mathrm{C}, \mathrm{m} .6962 \mathrm{G}>\mathrm{A}, \mathrm{m} .10310 \mathrm{G}>\mathrm{A}$ m.10609T>C, m.12406G>A, m.12882C > T, m.13928G $>C, \quad m .14668 C>T$, m.16129G $>A$, and m16304T $>C$ were not differentiated by the groups. However, $\mathrm{m} .16812 \mathrm{~A}>\mathrm{C}$ was more frequently observed in the patient group than control [22 $(22.4 \%)$ vs. $24(12.2 \%), p=0.061]$, and it was significantly associated with HLAB51 positivity $(p=0.011)$, arthralgia $(p=0.043)$ and methotrexate use $(p=0.02)$, and was not associated with uveitis in the follow-up study. Among clinical and laboratory characteristics in BD patients, thrombosis was more frequently observed in male patients than female patients $[7(22.6 \%)$ vs. $0(0 \%), p<0.001]$, and WBC counts were lower in female patients [3642.3 \pm 3413.6 vs. $5200.8 \pm 3912.7$, $\mathrm{p}=0.048]$

Abstract AB0009 - Table 1

\begin{tabular}{|c|c|c|c|c|c|}
\hline $\begin{array}{c}\text { RCRS } \\
\text { position }\end{array}$ & Alteration & $B D(n=98)$ & HC $(n=196)$ & $p$-value & $\mathrm{OR}^{*}(95 \% \mathrm{Cl})$ \\
\hline 248 & A del & $12(12.2 \%)$ & $23(11.7 \%)$ & 1.000 & $1.050(0.499 \sim 2.209)$ \\
\hline 304 & & $0(0 \%)$ & $0(0 \%)$ & NA & NA \\
\hline 709 & $G>A$ & 24 (24.5\%) & 35 (17.9\%) & 0.236 & $1.492(0.929 \sim 2.686)$ \\
\hline 3010 & $G>A$ & 19 (19.4\%) & $50(25.5 \%)$ & 0.307 & $0.702(0.387 \sim 1.273)$ \\
\hline 3970 & $\mathrm{~T}>\mathrm{C}$ & $14(1$ & 19 (9.7\%) & 0.327 & $1.553(0.743 \sim 3.246)$ \\
\hline 4883 & $C>T$ & 25 (25.5\%) & 59 (30.1\%) & 0.494 & $0.795(0.460 \sim 1.374)$ \\
\hline 5178 & $C>A$ & $25(25.5$ & $59(30.1$ & 0.494 & $0.795(0.460 \sim 1.374)$ \\
\hline 6392 & $\mathrm{~T}>\mathrm{C}$ & $14(14.3 \%)$ & 19 (9.7\%) & 0.327 & $1.553(0.743 \sim 3.246)$ \\
\hline 6962 & $G>A$ & $12(1$ & $18(9.2 \%)$ & 0.540 & $1.380(0.636 \sim 2.993)$ \\
\hline 10310 & $G>A$ & $16(1$ & $24(12$ & 0.434 & $1.398(0.705 \sim 2.774)$ \\
\hline 10609 & $\mathrm{~T}>\mathrm{C}$ & 12 (12.2\%) & $16(8.2 \%)$ & 0.361 & $1.570(0.711 \sim 3.463)$ \\
\hline 12406 & $G>A$ & $12(1$ & 17 (8.7\%) & 0.447 & $1.469(0.672 \sim 3.213)$ \\
\hline 12882 & $C>T$ & 12 (12.2\%) & $16(8.2 \%)$ & 0.361 & $1.570(0.711 \sim 3.463)$ \\
\hline 13928 & $\mathrm{G}>\mathrm{C}$ & $14(14.3 \%)$ & 19 (9.7\%) & 0.327 & $1.553(0.743 \sim 3.246)$ \\
\hline 14668 & $C>T$ & $19(19$ & 49 (25.0\%) & 0.353 & $0.722(0.398 \sim 1.310)$ \\
\hline 16129 & $G>A$ & $23(23.5 \%)$ & 42 (21.4\%) & 0.804 & $1.124(0.631 \sim 2.005)$ \\
\hline 16182 & $A>C$ & $22(22$ & $24(12.2 \%)$ & 0.061 & $2.062(1.089 \sim 3.906)$ \\
\hline 16183 & $A>C$ & 32 (32.7\%) & 42 (21.4\%) & 0.092 & $1.766(1.026 \sim 3.040)$ \\
\hline 16189 & $\mathrm{~T}>\mathrm{C}$ & 42 (42.9\%) & 64 (32.7\%) & 0.112 & $1.547(0.939 \sim 2.548)$ \\
\hline 16304 & $\mathrm{~T}>\mathrm{C}$ & 15 (15.3\%) & $18(9.2 \%)$ & 0.170 & $1.787(0.859 \sim 3.720)$ \\
\hline
\end{tabular}

Conclusions: We performed a follow-up study to validate possible associations between BD and 20 mtDNA alterations. m.16812A $>C$ could be associated with $\mathrm{BD}$ and its several clinical or laboratory characteristics a Korean population.

\section{REFERENCES}

[1] Xavier JM, Shafiee NM, Ghaderi F, Rosa A, Abdollahi BS, Nadji A, et al Association of mitochondrial polymorphism m.709G $>$ A with Behçet's dis ease. Ann Rheum Dis 2011;70:1514-6.

[2] Kwon $\mathrm{MH}$, Joung Cl. Genetic Associations of Mitochondrial DNA Polymorphisms with Behçet's Disease in a Korean Population: A Pilot Study. Rheum Dis 2016;23(1):23-9.

Acknowledgements: The current study was supported by the National Research Foundation of Korea funded by the Korean Government (grant no. NRF2017R1C1B2008199).

Disclosure of Interest: None declared

DOI: 10.1136/annrheumdis-2018-eular.1714

\section{AB0010 EVALUATION OF SENSITIVITY TO DNA DAMAGING AGENTS AND EFFICIENCY OF DNA REPAIR IN HUMAN PERIPHERAL BLOOD MONONUCLEAR CELLSFROM PATIENTS WITH DERMATOMYOSITIS AND POLYMYOSITIS}

O. Brzezinska ${ }^{1,2}$ A. Macieja ${ }^{3}$, A. Lewandowska-Polak ${ }^{1}$, J. Sarnik $^{3}$, M. Kubicka ${ }^{3}$, J. Makowska ${ }^{1}$, T. Popławski ${ }^{3} .{ }^{1}$ Department of Rheumatology, ${ }^{2}$ Department of Rheumatology, Immunology and Allergy, Medical Univercity of Lodz; ${ }^{3}$ Department of Molecular Genetics, University of Lodz, Łódź, Poland

Background: Idiopathic inflammatory myopathies (IIM) being one of the connec tive tissue diseases are a group of diseases with not fully understood pathology The common features are production of autoantibodies, abnormal immune response against self-antigens and inflammatory process leading to destruction of muscle cells and internal organ involvement. Patients with inflammatory myopathies have higher risk of developing cancers. One of the processes that can 